\title{
EL MUSEO PEDAGÓGICO DE ARAGÓN. ALGUNAS CONSIDERACIONES SOBRE SUS DIEZ PRIMEROS AÑOS DE FUNCIONAMIENTO
}

\section{The Pedagogic Museum of Aragon. Some thoughts on its first ten years of active life}

\author{
Víctor JUAN BORROY \\ Director del Museo Pedagógico de Aragón \\ Universidad de Zaragoza \\ Correo-e:vjuan@unizar.es \\ Recepción: Io de noviembre de 2015 \\ Envío a informantes: Is de noviembre de 2015 \\ Aceptación definitiva: II de diciembre de 2015
}

Resumen: El Museo Pedagógico de Aragón cumplirá en la primavera de 2016 diez años. En este artículo se ofrece un breve resumen del trabajo realizado durante este tiempo, con especial incidencia en algunos indicadores relevantes para valorar la labor desarrollada por el museo: el número de visitantes que el museo ha recibido, las piezas que forman la colección, el sistema de catalogación, las publicaciones del Museo Pedagógico de Aragón -reflejo de la investigación y de la difusión que se ha hecho del patrimonio histórico pedagógico- o los préstamos temporales de piezas para exposiciones organizadas por otras instituciones, entre otros.

Finalmente el autor, desde los diez años de experiencia en la dirección del museo, plantea una serie de reflexiones sobre cuestiones que no había tenido en cuenta antes de dirigir el Museo Pedagógico de Aragón y que pueden ser útiles a las personas interesadas en los museos pedagógicos y en la conservación y difusión del patrimonio histórico educativo.

Palabras clave: Museo Pedagógico de Aragón; patrimonio histórico educativo; catalogación; Domus; exposición; difusión.

Abstract: The Pedagogical Museum of Aragon will be io years old in spring 2016. In this paper, a brief summary of the work done during this period of time is set out, paying particular attention to some relevant signs to assess the work achieved by the museum such as the number of visits, items comprising the museum's collection, cataloguing system, works published by the Pedagogical Museum of Aragon -which reflect the research and diffusion activities of the educational-historical heritage that have been undertaken- or temporary loans for exhibitions organised by other institutions. 
Finally, the author will present a series of considerations on matters he had not taken into account before being appointed Director of the Pedagogical Museum of Aragon. These may be useful for those interested in pedagogical museums and the preservation and diffusion of the educational-historical heritage.

KeY wORDs: Pedagogical Museum of Aragon; educational-historical heritage; cataloguing; Domus; exhibition; diffusion.

\section{Introducción}

$\mathrm{E}$ N MAYO De 2016 SE CUMPlirán Diez AÑos de la creación del Museo Pedagógico de Aragón ${ }^{1}$. Aunque una década es un período muy corto para una institución, es un tiempo suficiente para valorar lo que se ha hecho y plantear nuevos proyectos, nuevos retos ${ }^{2}$.

El profesor Julio Ruiz Berrio, en un trabajo ya clásico, sostiene que pueden distinguirse varios tipos de museos de la educación: Escuela museo, Museo histórico escolar, Museo de la educación, Museo pedagógico, Museo laboratorio de historia de la educación (Ruiz Berrio, 2002). Coincido con Pablo Álvarez cuando sostiene que no siempre es fácil encasillar a los museos dedicados al patrimonio histórico educativo existentes en una de las tipologías anteriormente expuestas, puesto que encontramos iniciativas museísticas que participan de las características y objetivos de varios de los tipos establecidos por Julio Ruiz Berrio (Álvarez Domínguez, 2oro). Y esta dificultad de adscripción la encontramos al intentar encuadrar al Museo Pedagógico de Aragón en una de esas categorías. La razón principal quizá pueda encontrarse en que, como destacaré enseguida, el Museo Pedagógico de Aragón no ha renunciado a nada: tenemos un espacio expositivo abierto al público, tenemos una gran colección de materiales de enseñanza y mobiliario escolar, hemos impulsado estudios e investigaciones, nuestra colección comprende varios miles de libros sobre educación, somos un centro de documentación, recreamos aulas de distintas épocas, etc.

Durante los diez primeros años de funcionamiento, el Museo Pedagógico de Aragón ha contribuido a la recuperación y difusión del patrimonio histórico educativo de Aragón (las biografías de maestros, las iniciativas pedagógicas que florecieron en Aragón, los principios que guiaron la política educativa en cada etapa histórica, las distintas concepciones de la infancia...). El Museo Pedagógico nos ha permitido recorrer un territorio por el que jamás nos habíamos adentrado. Durante estos diez años nos hemos contado historias que no nos habíamos contado nunca. Y lo más importante

El decreto de creación del Museo Pedagógico de Aragón se publicó en el Boletín Oficial de Aragón el 16 de mayo de 2006 y el museo se inauguró el i8 de mayo, coincidiendo con el Día Internacional de los Museos.

Almau, Amelia (2008) Entrevista a Víctor Juan. Director del Museo Pedagógico de Aragón. Cuadernos de Pedagogía, 380, junio, 42-47. Además en estos diez años he tenido ocasión de explicar el proyecto Museo Pedagógico de Aragón en artículos publicados en distintos lugares: Juan, Víctor (2007) Museo Pedagógico de Aragón. Virutas de un proyecto. En Agustín Escolano (ed.) La cultura material de la escuela. En el centenario de la Junta para la Ampliación de Estudios (1907-2007). Salamanca: CEINCE; JuAn, Víctor (2008) Los secretos del Museo Pedagógico de Aragón. Foro de Educación, Io, 495-499; JuAn, Víctor (20Io) El Museo Pedagógico de Aragón. El sentido de un proyecto. Aragón Educa. Revista del Museo Pedagógico de Aragón, I, 82-92; Juan, Víctor (2012) El Museo Pedagógico de Aragón. Un territorio para repensar y soñar la educación. La Magia de Viajar, 71, mayo-junio, 56-63. 
VÍCTOR JUAN BORROY

es que estas historias no solo nos permiten conocer mejor nuestro pasado, sino que son necesarias para entender el presente. Compartimos la idea de que somos lo que hemos sido y nuestro pasado no está detrás de nosotros sino ante nosotros. En este sentido, el Museo Pedagógico de Aragón quiere ser un espacio para la reflexión, para el debate y para soñar la educación que precisamos. La recuperación de nuestra historia educativa es esencial para diseñar el futuro de la educación. Estamos convencidos de que sin memoria no puede haber una auténtica innovación.

Una de las ideas que explica el trabajo que hemos realizado durante este tiempo en el Museo Pedagógico de Aragón es, sin duda, que no hemos renunciado a nada. Hemos querido atender todos los ámbitos de actuación sin esperar a consolidar unas áreas y posponiendo el trabajo en otras. Frente a una idea secuencial, hemos optado por el planteamiento global. Así, no hemos esperado a terminar de catalogar la colección para hacer actividades didácticas o para investigar y difundir algunos elementos esenciales de nuestro patrimonio histórico educativo. No hemos esperado a disponer de espacios para el adecuado almacenaje de nuestra colección para aceptar donaciones de algunos materiales que, de no conservarse en el museo, se hubieran perdido, con toda seguridad, para siempre.

Ofreceré a continuación datos sobre algunos de los indicadores que me parecen relevantes para valorar el trabajo que el Museo Pedagógico de Aragón ha realizado desde su creación. Junto a estas cifras también haré algunas reflexiones sobre la colección del Museo Pedagógico de Aragón, los visitantes, las actividades didácticas que realizamos, las exposiciones en las que hemos colaborado prestando algunas de nuestras piezas - muchas, como se verá- y, finalmente, nos ocuparemos de las publicaciones del Museo Pedagógico de Aragón, que han sido un instrumento muy importante para difundir la investigación que durante estos diez años hemos generado.

\section{La colección del Museo Pedagógico de Aragón}

Cuando el museo abrió sus puertas nadie sabía a ciencia cierta cuántas piezas integraban la colección porque no se había hecho un inventario de los objetos que se habían reunido desde finales de los años ochenta3. Puede decirse que en aquel momento el Museo Pedagógico de Aragón tenía una «re-colección» de piezas procedentes, fundamentalmente, de escuelas que por distintas causas habían cerrado sus puertas $^{4}$. Pocas semanas después de su inauguración, el Museo Pedagógico comenzó a catalogar las piezas de su colección en Domus's. En primer lugar se inventariaron

\footnotetext{
Rafael Jiménez Martínez, director entonces del Centro de Profesores de Huesca, reunió las piezas con las que abrió sus puertas el Museo Pedagógico de Aragón.

4 Lamentablemente, Aragón es un territorio en el que desde los años sesenta se cerraron muchas escuelas en el medio rural debido al cambio de vida que se produjo durante esa época y al consiguiente éxodo del campo a las ciudades. Nos ocupamos de este tema en la primera exposición temporal del Museo Pedagógico de Aragón, origen del libro vv. AA. (2007) Escuelas. El tiempo detenido. Zaragoza: Prames/ Museo Pedagógico de Aragón.

Cuando se abrió el Museo Pedagógico de Aragón, la Dirección General de Patrimonio Cultural del Gobierno de Aragón estableció como una de las líneas prioritarias de trabajo que todas las colecciones de los museos aragoneses se gestionaran con el sistema Domus, adoptado por el Museo de Cultura para la gestión de sus colecciones. Sobre el sistema domus puede consultarse Carretero, Andrés; Chinchilla, Marina; Barraca, Pilar; Adellac, María Dolores; Pesquera, Isabel y Alquézar, Eva María (I996)
} 
y catalogaron las aproximadamente mil cuatrocientas piezas que formaban la exposición permanente. Después se inició la catalogación de los fondos depositados en los almacenes.

En septiembre de 20I5, la colección del Museo Pedagógico de Aragón estaba formada por I4.098 piezas, catalogadas en Domus. Entre las piezas que forman la colección merece la pena destacar los 8.000 libros, 500 cuadernos escolares, 250 mapas, 50 globos terráqueos y esferas armilares, mobiliario escolar (pupitres, mesas y sillas del profesor, pizarras...), material didáctico para la enseñanza-aprendizaje de todas las áreas, documentos administrativos relativos al funcionamiento de las escuelas (correspondencia oficial, documentos del profesorado...), fotografías, material del alumno (carteras, útiles de escritura...).

La colección del Museo Pedagógico de Aragón continúa incrementándose con piezas que proceden, fundamentalmente, de materiales antiguos que recibimos de las escuelas y de donaciones de personas que, tras visitar el museo y comprobar el tratamiento que les damos a las fotografías, a los cuadernos escolares, a las labores o a los libros, deciden donar o ceder al museo los materiales que guardan en sus casas para que estén a disposición de todos. Desde su inauguración, el Museo Pedagógico de Aragón cuenta con II.I23 piezas más, procedentes de 165 donaciones de particulares o de centros docentes. Estas donaciones son una muestra de la complicidad de personas e instituciones con el Museo Pedagógico de Aragón.

\section{Los visitantes}

El colectivo principal al que va dirigido el discurso del Museo Pedagógico de Aragón es el formado por escolares, profesores y estudiantes de todos los niveles educativos. Normalmente, cuando acuden en grupos solicitan una visita guiada $y$, frecuentemente, realizan uno de nuestros talleres. Además, muchos turistas que pasan por la ciudad se encuentran, inesperadamente, con un museo y deciden recorrer nuestra exposición permanente. Una de las características del Museo Pedagógico de Aragón es que se explica solo. Todo el mundo ha pasado por la escuela y los espacios que se recrean en el museo son siempre familiares porque cualquier persona puede relacionar lo que ve con su propia experiencia para encontrarle un significado. Aunque no es necesaria una formación específica para encontrarle sentido a la exposición, cuando el personal del museo realiza una visita guiada se comentan detalles que a los visitantes que recorren las secciones libremente seguro que pasan desapercibidos.

\footnotetext{
Normalización documental de museos: elementos para una aplicación informática de gestión museográfica. Madrid: Ministerio de Educación y Cultura, véase en http://www.mcu.es/museos/MC/NDM/index.html (consultado el i de diciembre de 20I5) y CARRASCo GARRIDO, Reyes (20IO) Un modelo de normalización documental para los museos españoles: Domus y la Red Digital de Colecciones de Museos de España. En Actas del Seminario de Investigación en Museología de los países de habla portuguesa y Española, vol. I. Universidad de Oporto. Las líneas básicas de este proceso en Aragón pueden consultarse en vv. AA. (2009) Gestión y planificación museística. DOMUs en Aragón. Actas de las I Jornadas de Museos Aragoneses, Zaragoza, 20-22 de mayo de 2009. Zaragoza: Departamento de Educación Cultura y Deporte de Gobierno de Aragón, véase en http://www.dehuesca.es/ sipca/IMAGEN/documentos_web/BDPCA_25.pdf (consultado el 20 de octubre de 20I5).
} 
EL MUSEO PEDAGÓGICO DE ARAGÓN. ALGUNAS CONSIDERACIONES SOBRE SUS DIEZ PRIMEROS AÑOS DE FUNCIONAMIENTO VÍCTOR JUAN BORROY

El Museo Pedagógico de Aragón ha recibido desde su apertura en mayo de 2006 hasta septiembre de 2015 un total de 19.942 visitantes $^{6}$.

\section{Actividades didácticas del Museo Pedagógico de Aragón}

El Museo Pedagógico de Aragón ofrece la posibilidad de realizar actividades didácticas, diseñadas y dirigidas por el personal del museo, que siempre se ajustan a la edad de los visitantes. Hemos pretendido que estos «cuentos» empiecen y terminen en el museo. No hemos querido caer en el didactismo. No hemos querido abordar en el museo contenidos escolares de cada una de las etapas educativas. Por ejemplo, al hablar de Costa no damos una lección sobre la Restauración, el regeneracionismo o la crisis del noventa y ocho. Contamos una historia que empieza y termina en el museo. Lo mismo cabe decir de la actividad sobre el Sistema Métrico Decimal. Los niños no aprenden a pasar de metros a centímetros. Eso lo harán en clase, con sus maestros. Nosotros, partiendo de nuestras piezas, contamos una historia sobre el sentido del Sistema Métrico Decimal. A continuación, resumiré el contenido y los objetivos de cada una de las actividades didácticas que actualmente oferta el Museo Pedagógico de Aragón.

\section{I. Si no puedo estudiar, no quiero vivir. Joaquín Costa y la educación}

Los artistas que han representado a Joaquín Costa en lienzos, esculturas y dibujos han idealizado su imagen, silenciando detalles de su vida al considerar que eran circunstancias sin interés o que empequeñecían al gran hombre. En el Museo Pedagógico de Aragón queremos recuperar el lado más humano de Costa, queremos acercarnos al hombre despojado de calificativos grandilocuentes. Quizá la primera condición para entender a Costa sea descubrir al hombre que tuvo sueños, fue feliz, se sintió solo, estuvo triste, tuvo amigos, se enamoró, superó las dificultades. El legado de Costa se resume en su pasión por el conocimiento.

$\mathrm{La}$ actividad incluye un pequeño recorrido por la exposición permanente del museo fijándose especialmente en todo el material que hace referencia a la didáctica, para después participar en una sesión narrada con apoyo audiovisual en torno a la afirmación de Joaquín Costa: «Si no puedo estudiar, no quiero vivir».

Dirigida preferentemente a estudiantes de último ciclo de Primaria, Secundaria y Bachillerato.

\subsection{Recortables para muñecas de Ramón Acín}

Esta actividad pretende acercar la figura del pedagogo Ramón Acín a los participantes, mediante el conocimiento de su vida, de su forma de ser y de enseñar, de su familia, sus discípulos y amigos... Ramón Acín diseñó una mesa pupitre para la

6 Para valorar adecuadamente la cifra de visitantes hay que tener en cuenta que, por razones presupuestarias, desde 2013 los días que el museo abre al público se redujeron a la mitad (miércoles, jueves y viernes de $9 \mathrm{~h}$ a $20 \mathrm{~h}$ ). 
enseñanza del dibujo y también unas figuras recortables para sus hijas, que los visitantes reproducirán a partir de una plantilla de madera.

Se plantea la exposición en tres niveles distintos para ajustar la información a la edad de los visitantes.

\subsection{Transformar el mundo con palabras. La imprenta Freinet en Aragón}

En Aragón, durante los años treinta del siglo xx, se desarrollaron interesantes experiencias con la imprenta escolar. En el Museo Pedagógico de Aragón hemos querido contar lo que aquella manera de entender la escuela y la sociedad representó. Recuperamos así la trayectoria vital y profesional de los protagonistas de esta historia: Simeón Omella, Herminio Almendros, José Bonet Sarasa, Freinet y, por supuesto, leemos algunos de los hermosos textos libres que los escolares de Plasencia del Monte, Barbastro o Agüero compusieron letra a letra.

Después de contarles parte de la historia de la imprenta escolar en Aragón, los visitantes elaboran una carpeta y se les invita a guardar en ella los textos que escriban para reflexionar, para contarse el mundo y, por lo tanto, para apropiarse de él.

Dirigida preferentemente a alumnado de Primaria, Secundaria y Bachillerato.

\subsection{Cien años de Escuela}

La escuela es el espejo del alma de una sociedad. Con esta actividad pretendemos repasar los principales hitos de la historia de Aragón y de España durante el siglo xx, analizando las principales características de la institución escolar y del sistema educativo. Se presenta un multimedia en el que a través de imágenes de escuelas, profesores, manuales escolares, grupos de estudiantes, etc., hacemos un recorrido por los principales períodos que pueden distinguirse en el siglo xx:

La edad de oro de la Pedagogía.

La II República.

La Guerra Civil y la dictadura del general Franco.

La recuperación de las libertades.

Esta actividad va dirigida preferentemente a estudiantes de Educación Secundaria Obligatoria y de Bachillerato.

\subsection{Medir, pesar y contar: la historia del Sistema Métrico Decimal}

Con esta didáctica pretendemos mostrar el caos y la confusión que suponía la utilización de un sistema de medidas distinto en cada lugar y cómo, por ello, surgió la necesidad de establecer un sistema uniforme para todos: el sistema métrico decimal.

Los grupos visitan la exposición permanente descubriendo el material didáctico, los libros y los trabajos escolares que se han utilizado y realizado para la enseñanza y el aprendizaje de estos contenidos curriculares. Posteriormente, escuchan un romance de ciego y conocen instrumentos de medida que actualmente están en desuso.

Dirigida preferentemente a alumnado de Educación Infantil y Primaria. 
EL MUSEO PEDAGÓGICO DE ARAGÓN. ALGUNAS CONSIDERACIONES

SOBRE SUS DIEZ PRIMEROS AÑOS DE FUNCIONAMIENTO

VÍCTOR JUAN BORROY

\section{Exposiciones y préstamo de piezas}

Hasta mayo de 20I5, el Museo Pedagógico de Aragón había prestado temporalmente dos mil trescientas noventa piezas que se expusieron en las cuarenta y dos exposiciones y veintisiete actos de distinta índole (jornadas, semanas culturales, encuentros científicos, aniversarios...) en los que el museo ha colaborado dentro y fuera de Aragón. Este número de piezas prestadas es una cifra difícil de alcanzar por cualquier otro museo. Hay que tener en cuenta, naturalmente, la naturaleza de nuestra colección. Distintas instituciones han organizado exposiciones en las que se abordaba un período histórico determinado y para «retratar» la sociedad del momento -ninguna institución refleja de una manera tan fiel como la escuela los valores de cada sociedadhan recreado en la exposición un aula de la época7.

\section{Los libros editados por el Museo Pedagógico de Aragón}

Cuando el Gobierno de Aragón creó el Museo Pedagógico no solo se acondicionó un espacio para exposición y salvaguarda del patrimonio histórico educativo aragonés. Al mismo tiempo se creó un espacio simbólico para la reflexión, el debate y la investigación. Este espacio lo hemos habilitado, fundamentalmente, con las publicaciones editadas por el Museo Pedagógico, un conjunto de libros y de distintos materiales que nos han permitido recuperar la biografía de educadores aragoneses, las iniciativas pedagógicas que florecieron en Aragón, las ideas que animaron algunos proyectos educativos... En alguna ocasión ya he defendido que este espacio es, aunque no se pueda visitar, la sala más importante del museo. Nuestras publicaciones se han distribuido por todas las universidades del Estado y han sido muy valoradas por profesores e investigadores. Defendemos que estos libros -analógicos y digitalestambién son una parte esencial del Museo Pedagógico de Aragón.

Actualmente, el Museo Pedagógico cuenta con dos colecciones: Publicaciones del Museo Pedagógico de Aragón, en la que se han editado veintitrés números ${ }^{8}$.

Por ejemplo, del I6 abril de 2015 al 28 de junio pudo visitarse la exposición Cuarenta años con Franco (comisario de la exposición Julián Casanova), organizada por el Ayuntamiento de Zaragoza. En esta exposición podía contemplarse un aula del nacional-catolicismo recreada con ochenta y siete piezas procedentes de la colección del Museo Pedagógico de Aragón.

8 Estos son los títulos, ordenados en orden inverso al de su aparición: Cartilla para escribir en seis días (20I2, primera y segunda parte), Letra a letra (20II), Grupo Escolar Costa Zaragoza. Colección I8 postales. Serie 2." (20II), Grupo Escolar Costa Zaragoza. Colección I8 postales. Serie r. ${ }^{a}$ (20II), Miguel Vallés. Entre Pedagogía y Didáctica. Artículos en la prensa del Magisterio turolense (I870-1920) (2010), Páginas originales. (Memorias de un maestro de escuela) (2010), Las mujeres de mañana (2009), Hipocorísticos. Ochenta y cuatro crónicas sobre Educación de Personas Adultas en Aragón (2009), Pasión por lo cotidiano. La maestra turolense Máxima Oliver Royo en la fundación del Museo Etnológico Nacional (2009), Los secretos del Museo Pedagógico de Aragón. Guía de urgencia (2009), Nuevo Aragón de 9 de marzo de 1937, Plan de primera educación. Huesca, I820 (2009), Escuelas. La educación en el medio rural aragonés en imágenes (2009), Transformar el mundo desde la escuela con palabras. Los cuadernos freinetianos de Barbastro durante la II República (2008), La fiesta del Árbol (2008), Museos Pedagógicos. La memoria recuperada, (2008), Zaragoza 1908. El Congreso Nacional Pedagógico (2008), Los Sitios de Zaragoza (2008), Apuntes de Geografía. Aragón (2008), Los niños del frente (2007), Escuelas. El tiempo detenido (2007), El libro de los escolares de Plasencia del Monte (2007). Un breve resumen del contenido de estos libros acompañado de cada una de las cubiertas puede verse en la sección dedicada a «Publicaciones» en la página web del Museo Pedagógico de Aragón: http://www.museopedagogicodearagon.com/publicaciones.php. 
EL MUSEO PEDAGÓgICO DE ARAGÓN. ALGUNAS CONSIDERACIONES SOBRE SUS DIEZ PRIMEROS AÑOS DE FUNCIONAMIENTO VÍCTOR JUAN BORROY

La colección Publicaciones Digitales del Museo Pedagógico de Aragón está alojada en la página web del museo, donde pueden descargarse gratuitamente los libros?.

El primer título de la colección, Diario de un aprendiz de maestro, de José Luis Capilla, se publicó en mayo de 2013 y el último, Para la Fiesta del Árbol, una edición facsímil que el maestro de Huesca Manuel Ascaso Ciria editó en 1923, se publicó en nuestra colección en abril de 20I5. En total, desde mayo de 2013 hasta septiembre de 2015 nuestros libros digitales se han descargado 3.435 veces. Creemos que esta colección es un buen instrumento para difundir el trabajo que hacemos en el museo y para acercar nuestro patrimonio histórico educativo al público ${ }^{\mathrm{io}}$.

\section{I. Aragón Educa. Revista del Museo Pedagógico de Aragón}

En 2010 presentamos al Departamento de Educación, Cultura y Deporte del Gobierno de Aragón el proyecto de publicación de una revista en la que pretendíamos trabajar en tres ámbitos:

a. El patrimonio histórico educativo. Daríamos a conocer la investigación propia del trabajo que el Museo Pedagógico de Aragón realizaba. También acercaríamos las actividades que los escolares podían hacer en los museos aragoneses.

b. Aragón Educa. Revista del Museo Pedagógico de Aragón sería, además, un instrumento para que los profesores aragoneses dieran a conocer sus reflexiones, el resultado de sus investigaciones y experiencias.

c. La revista de Museo Pedagógico sería un medio para que el Departamento de Educación, Cultura y Deporte diera a conocer sus más importantes programas: la formación profesional, las enseñanzas artísticas, el aprendizaje de lenguas extranjeras... Además en cada número se incluía media docena de páginas con publicidad exclusivamente institucional (campañas de deporte escolar, animación a la lectura, participación en el Consejo Escolar, seminarios, jornadas y congresos, etc.).

Se editaron tres números de la revista semestral (marzo de 20Io, septiembre de 20II, marzo de 20II). Cada número de la revista se acompañaba de un ejemplar de la colección Encartes del Museo Pedagógico de Aragón ${ }^{\mathrm{II}}$.

Se imprimían tres mil ejemplares de cada número de Aragón Educa. Revista del Museo Pedagógico de Aragón. Se enviaba un ejemplar de la revista a cada uno de los centros docentes no universitarios de Aragón. Además, la revista se repartía entre los asistentes a las celebraciones del Día de la Educación Aragonesa y servía como

9 Los libros de la colección Publicaciones Digitales del Museo Pedagógico de Aragón pueden descargarse gratuitamente en http://www.museopedagogicodearagon.com/publicacionesdigitales.php.

1o Los libros de esta colección son los siguientes: Para la Fiesta del Árbol (2015), Si no puedo estudiar, no quiero vivir. Joaquín Costa y la Educación (2014), Los secretos del Museo Pedagógico de Aragón. Guía de Urgencia (2014), Esplicación del Sistema Métrico Decimal de pesas y medidas y monedas legales (2014), El Magisterio de Aragón a su fundador (2013), Ramón Acín y la Junta para Ampliación de Estudios (2013), La puesta en marcha de un gran Grupo Escolar (2013), Maestros en el caleidoscopio (2013), Diario de un aprendiz de maestro (2013).

II Se publicaron tres números de esta colección: Ramón Acín y la JAE (2010), Álbum de fotografías (20I0) y el último número dedicado a Joaquín Costa: Ideas apuntadas sobre Joaquín Costa. En el centenario de su muerte (20II). 
EL MUSEO PEDAGÓGICO DE ARAGÓN. ALGUNAS CONSIDERACIONES SOBRE SUS DIEZ PRIMEROS AÑOS DE FUNCIONAMIENTO VÍCTOR JUAN BORROY

regalo protocolario para actividades en las que convenía dar a conocer algunos de los proyectos que se realizaban en el sistema educativo aragonés.

\section{Diez cosas que he aprendido en diez años y una reflexión sobre museos pedagógicos instalados en escuelas rurales}

Me propongo anotar en este apartado una serie de ideas que la experiencia de dirigir el Museo Pedagógico de Aragón me ha suscitado a lo largo de estos diez años. Confesaré que algunas de las cuestiones que expondré no me las había planteado antes de enfrentarme diariamente a las exigencias de un museo. Por eso creo que pueden ser de alguna utilidad para las personas interesadas en el patrimonio histórico educativo. Finalmente, haré una reflexión sobre el sentido y el funcionamiento del espacio que el Museo Pedagógico de Aragón tiene en Linás de Marcuello ${ }^{12}$, un pueblo de la provincia de Huesca, distante de la capital 30 kilómetros, en donde gracias al trabajo de Rafael Jiménez se acondicionó, antes de la creación del Museo Pedagógico de Aragón, un espacio expositivo dedicado a la escuela rural aprovechando la antigua casa del maestro y las aulas de la escuela.

\section{I. Evitar la nostalgia}

Los museos pedagógicos se explican por sí mismos porque representan un período y un espacio por el que todos hemos transitado. Los objetos que en ellos se muestran están o han estado presentes en la vida cotidiana de todos. No es raro que las personas conserven en su casa piezas importantes para un museo pedagógico: fotografías, labores, libros, cuadernos escolares, materiales didácticos -para la escritura, el cálculo, el dibujo, etc.-, boletines de notas, diplomas de premios... Las piezas de las que se nutren mayoritariamente los museos pedagógicos proceden de fondos públicos: el mobiliario escolar, el material administrativo, los libros de las bibliotecas escolares, el material didáctico enviado por las administraciones a las escuelas, pero en las colecciones de material histórico educativo también se encuentran con frecuencia materiales procedentes de donaciones o depósitos temporales de particulares.

Los museos pedagógicos también son lugares propensos al cultivo de la nostalgia. Aunque quiero dejar bien claro que para mí ese no es el enfoque que hay que darles a las colecciones de material escolar. Creo que en educación es evidente que casi siempre cualquier tiempo pasado fue peor. Los museos pedagógicos devuelven a muchos de sus visitantes a la infancia y corremos el riesgo de dejarnos seducir por el recuerdo de un tiempo perdido, por el recuerdo de las personas que nos acompañaron, por el recuerdo del niño que ya no volveremos a ser y, como canta La Ronda de Boltaña, «el recuerdo vuelve tierno hasta el pan duro de ayer». Así hay quien añora las labores, los rezos, los cánticos, incluso el sabor de la leche en polvo, en una clara demostración de lo que supone unir la representación de un tipo de escuela con los recuerdos de un tiempo perdido, aunque no siempre fuera un tiempo totalmente feliz.

12 Linás de Marcuello es una localidad de la Comarca de La Hoya, perteneciente al municipio de Loarre. Actualmente, Linás de Marcuello tiene una treintena de habitantes. 
EL MUSEO PEDAGÓGICO DE ARAGÓN. ALGUNAS CONSIDERACIONES SOBRE SUS DIEZ PRIMEROS AÑOS DE FUNCIONAMIENTO VÍCTOR JUAN BORROY

\subsection{La mirada del historiador es necesaria, pero no suficiente}

En un museo pedagógico es necesario contar con el concurso de personal técnicamente cualificado en el ámbito de la gestión del patrimonio y, en concreto, en la gestión de museos. No basta la visión del historiador de la educación, aunque un historiador de la educación es, sin duda, el encargado de darles sentido a los objetos, a los espacios y quien está en mejores condiciones de proponer un discurso coherente para la exposición permanente. Un museo pedagógico debería contar con documentalistas y especialistas en biblioteconomía para el archivo de libros, documentos manuscritos -memorias, correspondencia oficial y privada, informes, memorias, diarios, etc.- y documentación administrativa. En un museo pedagógico son absolutamente necesarios los técnicos en conservación y restauración que velen por las adecuadas condiciones de exposición, almacenamiento y transporte de unas piezas que son más sensibles de lo que casi siempre suele pensarse. También se necesita personal cualificado -maestros o educadores de museo- para realizar las visitas guiadas y las actividades didácticas.

\subsection{Colección versus re-colección. El museo es su colección}

Un museo convierte cada pieza de su colección en bien patrimonial. En el caso de un museo pedagógico, podría decirse que un lapicero, un cuaderno escolar, una lámina de dibujo o el oficio de toma de posesión de un maestro no tienen un gran valor material. Y muchas personas compartirían esta idea. Pero cuando un objeto, por pequeño y humilde que sea, forma parte de la colección de un museo, es decir, se le da un número de inventario general de la colección y se le asigna un lugar, una ubicación, bien en la exposición, bien en el almacén del museo, esa pieza es un bien patrimonial y está protegida por las leyes de patrimonio.

Quizá parezca excesivamente radical mi planteamiento y, desde luego, asumo que es absolutamente discutible, pero si las piezas no están convenientemente catalogadas e inventariadas, no hay colección y, por lo tanto, no podemos decir que estemos ante un museo. En el caso de que las piezas no estén catalogadas quizá convenga hablar mejor de una re-colección -objetos recogidos aquí y allá, procedentes de varios lugares- que de una colección propiamente dicha. Estaremos ante un conjunto de piezas felizmente rescatadas y depositadas en salas, cajas y estanterías, pero no ante una colección que implica, insisto, la catalogación y a la asignación de un lugar determinado dentro del espacio físico del museo para poder recuperarla cuando así se precise. Actualmente todavía se podría reclamar una condición más a un museo: que su colección estuviera en red de forma que el catálogo y las fichas de cada pieza pudieran consultarse desde cualquier ordenador del mundo.

Durante estos años, en el Museo Pedagógico de Aragón, hemos aprendido a valorar nuestra colección, hemos entendido mejor lo que los objetos representan. También hemos llegado a algunas conclusiones sobre las piezas de nuestra colección. Señalaré ahora tres:

Las piezas del Museo Pedagógico de Aragón son transparentes. No analizamos exclusivamente lo que son, sino lo que representan. El valor de los materiales reside 
EL MUSEO PEDAGÓGICO DE ARAGÓN. ALGUNAS CONSIDERACIONES SOBRE SUS DIEZ PRIMEROS AÑOS DE FUNCIONAMIENTO VÍCTOR JUAN BORROY

en las historias que nos cuentan, en las historias que nos permiten contar. No son materiales exclusivos o valiosos por su rareza. El mundo escolar, el mundo de la cultura, en general, es un universo simbólico sometido a interpretación. El valor de nuestras piezas reside en que nos permiten analizar aspectos esenciales referidos a la educación y a la escuela. Durante estos diez años hemos aprendido a interrogar a las piezas y a escuchar los secretos que los objetos guardan, ya que en ellos se ha depositado la memoria de las personas, de las ideas, de los valores de una determinada época. Lo importante, en definitiva, no es el valor material de los objetos sino la interpretación de la realidad que puede hacerse partiendo de ellos.

Las piezas del Museo Pedagógico de Aragón son polivalentes y admiten varias lecturas. Un mismo objeto (un libro de texto, un pupitre, un cuaderno o una fotografía) nos sirve para mostrar y reflexionar sobre asuntos distintos: el modelo de infancia, el currículo establecido oficialmente, la manera de entender la institución escolar en una época determinada, los valores de una sociedad o el trabajo de los maestros. Otros materiales no son estrictamente pedagógicos, pero explican el contexto escolar. Por ejemplo, el brasero individual -fabricado frecuentemente sirviéndose de un recipiente metálico con asas para que los escolares no se quemaran al trasladarlo de su casa a la escuela- que los niños llevaban a la escuela para calentarse las manos y poder sostener la pluma no es estrictamente un material pedagógico, pero evidencia las carencias de la sociedad y la insuficiencia de los recursos destinados a las escuelas.

Las piezas del Museo Pedagógico de Aragón exigen un trabajo permanente. Es necesario investigar sobre los objetos para encontrar el sentido de cada pieza. Por eso quizá no hay nada tan transitorio y más sometido a cambios como nuestra llamada exposición permanente. Lo único permanentemente inacabado debe ser la búsqueda del sentido de cada pieza en el conjunto del discurso.

\subsection{Ni curiosidades ni rarezas}

En un museo pedagógico debe huirse de la anticuaria, de la exposición de objetos raros, curiosos o anecdóticos. Hemos de pretender que cada pieza contribuya al discurso general del museo, un discurso abierto y crítico.

\subsection{La exposición no lo es todo}

Frecuentemente cuando quienes no procedemos el ámbito museístico pensamos en un museo solo viene a nuestra mente el espacio expositivo que puede recorrerse, el espacio en el que se ordenaran las piezas coherentemente para ser mostradas a los visitantes, pero un museo tiene muchas más necesidades espaciales que las derivadas de la instalación de la exposición permanente. Ahora, tras estos diez años de experiencia en la dirección del Museo Pedagógico de Aragón, cuando pienso en un museo lo entiendo como un espacio abierto a la sociedad, como una institución que debe prestar un importante servicio a la comunidad. Además del espacio dedicado a la exposición es necesario contar con otras dependencias. Señalaré algunas. 
Biblioteca. Además de los fondos bibliográficos que forman parte de la colección del museo, un museo pedagógico debe aspirar a ser un centro de documentación sobre la escuela, la educación, el magisterio, etc., de manera que cualquier persona que emprenda una investigación histórico-pedagógica pueda recurrir al fondo documental del museo pedagógico: monografías, investigaciones, tesis doctorales, fotografías, etc.

Sala de investigadores. Destinada a personas que acudan al museo a consultar nuestros fondos. Me refiero, fundamentalmente, a la consulta de piezas no expuestas, pero que pueden ser de interés indudable para estudios monográficos. Lo normal es que el museo solo exponga una muestra de manuales escolares o de mapas o de cuadernos escolares. Las piezas no expuestas, convenientemente almacenadas, están a disposición de investigadores y estudiosos.

Salón de actos. En este espacio se organizarían conferencias, presentaciones de libros, jornadas, seminarios. Este espacio estaría a disposición de asociaciones y colectivos culturales para que pudieran celebrar allí sus actividades, previa solicitud a la dirección del museo.

Dependencias para restauración. Se precisa una sala para guardar las piezas que llegan al museo hasta que, después de inventariadas y catalogadas, se les asigna un número en el inventario general (NIG) y un lugar en la exposición permanente, en la biblioteca o en el almacén.

Salas para actividades didácticas y talleres. No es conveniente utilizar el espacio de la exposición permanente para las actividades didácticas. En muchas ocasiones coinciden grupos de visitantes y lo deseable sería que, por ejemplo, cuando un grupo está realizando un taller el otro pudiera recorrer la exposición permanente sin molestias ni interrupciones.

Almacén. Este espacio es clave para la buena marcha de un museo. Los almacenes son los cimientos que sustentan los museos. Nuestra experiencia nos dice que solo una pequeña parte de la colección de un museo se muestra en la exposición permanente. Es necesario disponer de un almacén suficiente donde guardar ordenadamente las piezas. Normalmente estas piezas almacenadas son las que se prestan temporalmente para algunas exposiciones. Hay que organizar la exposición permanente con criterios lógicos. Tomemos el ejemplo de los cuadernos escolares y de los mapas. En la exposición permanente no deben amontonarse las piezas. Se mostrarán las justas, las que permitan que los visitantes interpreten el discurso de la exposición permanente. Podemos mostrar ocho o diez cuadernos, pero lo deseable sería que el museo dispusiera de centenares o de miles de ejemplares porque son piezas importantes para entender la escuela, el currículum vivido por los escolares, los valores que se pretendía inculcar a los niños y el trabajo de los maestros ${ }^{13}$. De la misma manera,

13 Sobre la importancia de los cuadernos escolares como fuente para la Historia de la Educación pueden consultarse, por ejemplo, los siguientes trabajos: SANChidrí́n Blanco, M. ${ }^{a}$ Carmen y Gallego García, M. ${ }^{a}$ del Mar (2009) Los cuadernos escolares como fuente y tema de investigación en Historia de la Educación. En María Reyes Berruezo Albéniz y Susana Conejero López (coords.) El largo camino hacia una educación inclusiva: la educación especial y social del siglo XIX a nuestros días, XV Coloquio de Historia de la Educación (vol. 2, pp. 769-780). Pamplona: Universidad Pública de Navarra; Pozo, M.a del Mar del y Ramos, Sara (2007) Ir a la escuela en la guerra. El reflejo de la cotidianeidad en los cuadernos escolares. Cultura Escrita y Sociedad, 4, I29-I70; Viñao Frago, Antonio y Martínez Ruiz-Funes, María José (20II) Los cuadernos escolares y el arte de enseñar: el fondo del Centro de Estudios sobre la Memoria 
VÍCTOR JUAN BORROY

tampoco podemos forrar las paredes del espacio dedicado a exposición con los centenares de mapas que se conservan en el museo, pero todos los ejemplares deben estar perfectamente ubicados para su consulta.

Guardarropa. Los visitantes acuden al museo con los abrigos, las mochilas, el paraguas si llueve. Para recorrer la exposición ninguna de estas cosas es necesaria. Es conveniente contar con un espacio donde depositar todos esos elementos que pueden resultar incómodos a la hora de realizar la visita al museo o al participar en los talleres previstos.

Aula para clases. Lo ideal sería disponer de dos clases equipadas con pizarra, pantalla y cañón de proyección para dar allí clases o para que fueran el lugar de reunión de seminarios y grupos de trabajo.

Otros espacios recomendables. Además de los despachos y salas de trabajo del personal técnico del museo, deberíamos contar con dependencias para que los escolares o los visitantes pudieran estar/esperar en caso de lluvia. Baños suficientes y acondicionados para que puedan ser utilizados por grupos numerosos de personas entre quienes habrá niños y adultos.

\subsection{El continente también importa}

Hemos dicho ya algunas cosas sobre el contenido de un museo pedagógico. Nos ocuparemos ahora de las condiciones que debería cumplir el espacio destinado a museo pedagógico. Los diez años de experiencia al frente del Museo Pedagógico de Aragón me llevan a concluir que un museo pedagógico debería ubicarse en un centro educativo, en un espacio en donde las personas se hayan encontrado para enseñar y para aprender. Es justo en este espacio escolar (pasillos, aulas, escaleras, ventanas, baños, techos, despachos...) donde las piezas del museo van a mostrar de una manera más nítida su mensaje. Soy consciente de que no siempre se puede elegir ${ }^{14}$, pero, si existe la posibilidad de que el museo se instale en un centro escolar, hay que descartar antiguos cuarteles, hospitales, conventos, iglesias o cualquier otro edificio en desuso que quiera utilizarse. Siempre que sea posible hemos de preferir la realidad a una representación de la misma. Si disponemos de un edificio escolar, no tendremos que reproducir ni las aulas ni otras dependencias escolares ${ }^{15}$.

Educativa (ceme) de la Universidad de Murcia. En Pablo Celada Perandones (coord.) Arte y oficio de enseñar: dos siglos de perspectiva histórica. Xvi Coloquio Nacional de Historia de la Educación (vol. I, pp. 245-254). El Burgo de Osma: Sociedad Española de Historia de la Educación/Universidad de Valladolid y CEINCE, y el más reciente MARTín Fraile, Bienvenido y Ramos Ruiz, Isabel (20I5) La historia contada de los cuadernos escolares. Madrid: Ediciones La Catarata.

${ }^{14}$ Actualmente el Museo Pedagógico de Aragón está instalado en las dos plantas del antiguo mercado municipal de Huesca. Disponemos de ochocientos cincuenta metros cuadrados, en un emplazamiento muy céntrico, que favorece las visitas de turistas, pero no hay nada en ese espacio nos recuerde el lugar en el que estuvieron ubicadas nuestras piezas, el escenario en el que transcurren las historias que queremos contar, el territorio en el que nuestros visitantes fueron escolares.

is Un edificio escolar nos permitiría disponer, por ejemplo, de un patio de recreo. Así podríamos explicar el recreo como un espacio y un tiempo educativo. Podríamos hablar del descubrimiento del juego y podríamos practicar algunos juegos escolares tradicionales quizá hoy poco conocidos por los niños, cultivar un huerto escolar, etc. 


\subsection{La conservación, transporte, préstamos y depósitos de las piezas}

Un museo pedagógico debe seguir las mismas rutinas que el resto de los museos respecto a la necesidad de asegurar las piezas, contar con transporte especializado, seguir los procedimientos administrativos para la petición de piezas y el préstamo ${ }^{16}$.

Como ya he comentado anteriormente, quienes procedemos del ámbito de la historia de la educación no nos planteamos algunos problemas que el personal técnico de los museos tiene muy presentes. Estas cuestiones tienen que ver, fundamentalmente, con las condiciones de conservación, exposición y seguridad de las piezas (niveles de humedad, temperatura constante, la luz no lesiva para las piezas, sobre todo para el papel)... Además de que la exposición pueda visitarse, tanto el almacenamiento como la exposición exigen unas condiciones que pocas veces nos planteamos.

\subsection{Reconocimiento del valor del patrimonio histórico educativo}

La dignidad de cualquier museo -y en muchas ocasiones los museos pedagógicos aún han de pelear por conquistarla- hace que debamos huir de planteamientos bien intencionados, pero que, a la larga, van en contra de la consideración del proyecto y del trabajo que hacemos en el ámbito de la conservación y estudio del patrimonio histórico educativo. Esta idea he procurado tenerla siempre presente al solicitar determinados espacios o cuando hemos buscado que no se nos asignaran determinadas dependencias o responsabilidades. Es una cuestión de rigor y de proyección de un proyecto. Los museos pedagógicos aún tenemos que conquistar ese espacio. Aún hay quien pone en duda que nuestros fondos sean un bien patrimonial. Quizá entre nuestros colegas, no, pero sí en el entorno museístico y entre la administración encargada de gestionar el patrimonio.

\subsection{La exposición, abierta del público}

Un museo debe estar abierto al público, a los estudiosos y a los investigadores. Si el museo no puede visitarse podemos decir que el patrimonio que allí se ha reunido está secuestrado. Un museo debe ofrecer un horario de visitas estable y suficiente para cumplir con una de las funciones principales de un museo: la difusión del patrimonio.

\section{Io. La investigación}

Una de las funciones de un museo es contribuir al estudio y a la investigación de su ámbito. Así los museos pedagógicos deberían impulsar la investigación sobre

${ }^{16}$ Respecto al préstamo de piezas, en el Museo Pedagógico de Aragón se sigue el mismo procedimiento que en el resto de los centros integrados en la red de museos del Gobierno de Aragón en lo referente a plazos de solicitud, informes, autorización del Departamento de Educación, Cultura y Deporte del Gobierno de Aragón tras considerar las medidas de seguridad y de conservación del espacio en el que se va a exponer la pieza. Además, ningún objeto de la colección puede salir del museo sin estar asegurado y sin la autorización del préstamo por parte de la Dirección General de Patrimonio Cultural. Los seguros y el transporte ha de pagarlos el solicitante del préstamo temporal. En el Museo Pedagógico de Aragón hacemos una valoración económica de las piezas solicitadas y el seguro ha de cubrir esa cantidad. 
EL MUSEO PEDAGÓGICO DE ARAGÓN. ALGUNAS CONSIDERACIONES SOBRE SUS DIEZ PRIMEROS AÑOS DE FUNCIONAMIENTO VÍCTOR JUAN BORROY

las piezas, sobre lo que estas representan, sobre la cultura del período al que pertenece la colección, etc.

\section{II. Linás de Marcuello. Breve reflexión sobre museos pedagógicos instalados en escuelas rurales}

El modelo más extendido de escuela pública española ha sido una escuela rural, escasamente dotada, escuelas incompletas de maestro único, como le gustaba decir al pedagogo aragonés Santiago Hernández Ruiz (Hernández Ruiz, 1997; Tiana y Juan Borroy, 2002). Una escuela en la que los materiales del alumno pasaban de padres a hijos, una escuela que recibía pocas atenciones de la administración educativa. Pasaban los años y maestros como don Gregorio, el del cuento de Manuel Rivas, esperaban en vano que el Ministerio de Instrucción Publica enviara el microscopio que agrandaría la lengua de las mariposas (Rivas, 1998) o las láminas de historia sagrada que harían más amenas las explicaciones del maestro. Junto a esta realidad -y, a veces, quizá justo por ella- la escuela rural también ha sido el escenario en el que se ha desarrollado la innovación. Piénsese, por ejemplo, en cómo se extendió durante los años treinta la imprenta Freinet o en todas las propuestas que pretendían introducir la vida en la escuela estudiando el entorno más próximo para que los escolares pudieran apropiarse del mundo.

Así, si se quiere entender qué ha sido la institución escolar, la escuela a la que asistió la mayor parte de la población española, un museo pedagógico debe contemplar la realidad de la escuela rural. Además, hay un patrimonio histórico educativo depositado en los pueblos que difícilmente podrá trasladarse a un museo para ser conservado y expuesto allí. Un museo pedagógico ha de prestar atención al patrimonio histórico educativo conservado en las propias instituciones educativas (Rodríguez Guerrero, 20I0) y también a los edificios escolares, las casas del maestro, las eras donde se disfrutaba del recreo, la placa que anunciaba la proximidad de la escuela, la calle dedicada al maestro, etc., sin olvidar el valioso patrimonio inmaterial que representan la memoria y los testimonios de las personas que viven en el pueblo y que acudieron a la escuela ${ }^{17}$.

Podemos afirmar que la escuela rural es imprescindible para entender el oficio de maestro. No en vano de la zona rural proceden, mayoritariamente, las personas que cursan magisterio y quienes posteriormente desempeñan esta profesión. Además, los primeros destinos de los maestros suelen ser escuelas de pequeños pueblos. A pesar de estas circunstancias, los estudiantes de magisterio no reciben una formación específica para trabajar en el medio rural, para atender un grupo de alumnos de varias edades y para impartir casi todas las asignaturas que conforman el currículo de la educación primaria.

La escuela rural es esencial para entender la escuela y este patrimonio debería conservarse y mostrarse en su ecosistema. Las colecciones pedagógicas que ayudan a entender la escuela, el maestro, la infancia, los valores que cada sociedad ha impulsado

${ }^{17}$ Sobre la importancia del patrimonio educativo inmaterial puede consultarse el trabajo de YANES Cabrera, Cristina (20Io) El patrimonio educativo inmaterial. Propuesta para su recuperación y salvaguardia. En Julio Ruiz Berrio, op. cit., 63-99. 
deberían exponerse, conservarse y visitarse en el espacio y el lugar en el que las piezas tienen más sentido. Así, lo deseable sería, desde luego, que el museo contara con un espacio dedicado a la escuela rural. Nos aseguraríamos de esta manera que la exposición despertase los sentimientos y las sensaciones que se tenían en las aulas reales, asegurando la comunicación con el visitante. Como ha señalado el profesor José María Hernández Díaz, uno de los retos de los museos es precisamente despertar esos sentimientos y emociones:

De ahí que los lenguajes museológicos a distancia, a través de internet, por ejemplo, con frecuencia resulten semiológicamente neutros, porque no comunican, no suscitan emoción, sensaciones, porque no han sabido crear clima, se proponen, efectivamente desactivados. Frente a la frialdad obligada de este tipo de instrumentos informáticos, imprescindible por otra parte para trasladar información histórico-pedagógica, los expertos en semiótica y los informáticos, junto a los historiadores de la educación, han de esforzarse por construir artefactos capaces de despertar los sentimientos y sensaciones que se proponen en los códigos pedagógicos propios del aula, del establecimiento educativo (Hernández Díaz, 20II) ${ }^{18}$.

Ahora bien, las exigencias técnicas de un museo no siempre se pueden cumplir en un pequeño núcleo rural. Me estoy refiriendo, fundamentalmente, a las condiciones de conservación y de seguridad. Además, no es raro que estos pequeños espacios expositivos sólo abran durante períodos determinados y la mayor parte del año permanecen cerrados, aumentando en su interior la humedad que perjudica a las piezas. También hay que considerar que estos espacios instalados en pequeños núcleos rurales con muy pocos habitantes no cumplen con las medidas de seguridad exigibles a edificios que albergan objetos protegidos por la ley de patrimonio. También hay que valorar el número de visitantes que recibe un museo pedagógico rural. Como ya hemos señalado, una de las funciones que ha de cumplir un museo es la difusión del patrimonio. Y esta tarea se complica si el museo está en un pueblo pequeño, con limitaciones desde el punto de vista de la comunicación. A estos problemas se añade, en el caso de Linás de Marcuello, la dificultad que representa para los trabajadores del Museo Pedagógico de Aragón tener que atender un espacio que está a unos treinta kilómetros de su puesto de trabajo: problemas para desplazarse, dietas de desplazamiento, seguros de viaje que cubran estos desplazamientos, etc. A mi juicio, nos enfrentamos a un problema complejo, que exige complejas soluciones.

Por resumir de algún modo todas las consideraciones que ya he expuesto, creo que es complicado plantear un museo pedagógico rural autónomo, instalado en una pequeña población, que no dependa de un gran centro museístico que catalogue, presupueste las necesidades de conservación y seguridad, que organice exposiciones, visitas y el transporte de piezas. En mi opinión, lo oportuno sería que existiera un gran museo pedagógico desde el que se dirigiera la investigación sobre el patrimonio depositado y expuesto en la escuela rural. De esta manera quizá resultaría más fácil cumplir los requisitos técnicos que exige un museo y, al mismo tiempo, el patrimonio

18 A pesar de las limitaciones que expone el profesor José María Hernández Díaz, los museos virtuales se han extendido en los últimos años. Sobre los museos pedagógicos virtuales puede consultarse Collelldemont, Eulàlia (20I0) Los museos virtuales de educación en España. En Julio Ruiz Berrio, op. cit., 275-293 y Ossenbach Sauter, Gabriela y Somoza, Miguel (2010) Los museos pedagógicos virtuales y la enseñanza de la Historia de la Educación. En Julio Ruiz Berrio, op. cit., 295-320. 
se mostraría en su ecosistema, contribuyendo, además a reforzar la oferta cultural de pequeñas poblaciones.

\section{Bibliografía}

Álvarez Domínguez, Pablo (20I0) Nuevo concepto de los museos de Educación. En Julio RUIz BerRio El patrimonio histórico-educativo. Su conservación y estudio (pp. I39-167). Madrid: Biblioteca Nueva.

Hernández Díaz, José María (20ir) Etnografía escolar e Historia de la Educación. Pistas de aproximación. En Alejandro Mayordomo, Carmen Agulló y Gabriel García Fasquet El patrimoni historicoeducatiu valencià. V Jornades d'Historia de L'Educació valenciana. Alicante: CEIC Alfons el Vell/Universitat de València (pp. 65-96).

Hernández Ruiz, Santiago (1997) Una vida española del siglo XX. Memorias. (Edición e introducción de Víctor M. Juan Borroy). Zaragoza: Instituto de Ciencias de la Educación de la Universidad de Zaragoza.

Rivas, Manuel (1998) «La lengua de las mariposas». En Qué me quieres, amor (pp. 2I-4I). Madrid: Alfaguara.

Rodríguez Guerrero, Carmen (20IO) Actuaciones prioritarias para la conservación del patrimonio histórico de las instituciones educativas. En Julio RuIz BERrio, op. cit., pp. 255-273.

Ruiz Berrio Julio (2002), Pasado, presente y porvenir de los museos de la educación. En Agustín Escolano y José María Hernández Díaz (coords.) La memoria y el deseo. Cultura de la escuela y educación deseada (pp. 43-65). Valencia: Tirant Lo Blanch.

Tiana, Alejandro y Juan Borroy, Víctor (eds.) (2002) Santiago Hernández Ruiz (I9oI-I988) y la educación de su tiempo. Miradas desde un centenario. Zaragoza: Centro Asociado de la UNED de Calatayud. 